\title{
Water Quality Control from the Perspective of Water Supply System Users' Safety
}

\author{
Prof. PhD. ing. Janusz Ryszard Rak \\ and PhD. ing. Barbara Tchórzewska-Cieślak \\ Rzeszow University of Technology \\ Department of Water Supply and Sewage Systems, \\ Al. Powstańców Warszawy 6, 35-959 Rzeszów, \\ Poland
}

\section{Introduction}

It is believed that the modern concept of quality is derived from the definition of Cicero, who in the first century BC created the Latin term "qualitas", which meant a characteristic, property of the object. In the seventeenth century AD Descartes introduced the dualistic concept of quality, distinguishing the primary quality (weight, shape) and the secondary quality that comes from the senses (smell, flavour). After the Second World War, an American scientist W.E. Deming in Japan introduced a method of quality control. In turn, J.M. Juran defined quality as the degree to which a particular product meets the needs of the buyer. In this way a system of total quality management was created. As a result of scientific research and Japanese and American practical implementations, in the years 1985-1987 the ISO series 9000 were formed.

Polish accession to the European Union caused a significant increase in the interest in national quality standards in water companies, which is received highly positively by drinking water consumers. A creator of a probabilistic methodology for safety analysis of technical objects F.R. Framer said that the risk depends not only on the severity and extent of the possible failures, but also on their likelihood

The risk may be considered tolerable (controlled) when the growing loss corresponds to strongly decreasing likelihood of a serious failure or disaster (Haimes 2009).

"Defence in Depth Philosophy" relies on the use of multiple barriers for physical, technical, procedural and organizational security. The activation of any barrier causes reactions at the local levels of system security. Directive 98/83/EC of 3 November 1998 on the quality of water intended for human consumption has committed member states to monitoring the quality of water intended for human consumption (EPA 2006). Member States should take all necessary measures to ensure regular monitoring of water quality to verify that the water available to consumers meets the requirements of current international legal norms. In 2004 in the third edition of Guidelines for Drinking-Water Quality the WHO presented guidelines for the development of so-called Water Safety Plans (WSP) (WHO 2002, 2004). which are intended for collective systems of water supply, and which meet the requirements 
for protection of critical infrastructure, as well as direct standards for continuous supply people with water in the required amount, under appropriate pressure and quality consistent with current standards (Rosen et al.2008).

In 2009, the project of European standard prEN 15975-1:2009 Security of drinking water supply. Guidelines for risk and crisis management. Part 1 Crisis management which will be gradually introduced as standards in individual member states, was developed.

\section{Quality systems in the production of drinking water}

Guarantees and drinking water consumers' safety can be assured through the following quality systems (Hellier 2000,Rak 2003):

- $\quad$ managing for quality - Quality Management- (QM),

- hazard analysis at critical control points - Hazard Analysis Critical Control Points (HACCP),

- risk analysis and control of biological contamination - Risk Analysis Biocontamination Control - (RABC)

- $\quad$ good hygienic practice - (GHP),

- $\quad$ good manufacturing practice - (GMP),

- $\quad$ early warning for dangerous food - Rapid Alert System for Food -( RASF),

The rules of GHP and GMP are implemented before the introduction of HACCP (Hellier 2000).

Quality systems for the production of drinking water define such terms as (Johanson 2008, Rak 2009):

- threat - biological, chemical or physical factors that may occur in drinking water and cause the negative consequences to human health,

- monitoring - a system of processed observations, measurements and studies for a particular purpose, carried out on representative samples,

- risk - risk of the negative consequences to human health and the severity of such consequences as a result of the consumption of drinking water (Mays 2005),

- $\quad$ risk analysis - the procedure consisting of three interrelated elements, including risk assessment, risk management and information about risk,

- $\quad$ risk assessment - a scientifically based process consisting of three stages, including hazard identification, hazard characterization, exposure assessment and risk characteristic

- $\quad$ risk management - the proceedings of the competent authorities providing ways of risk prevention and control, based on risk assessment and the applicable requirements for sanitary-hygienic safety in the production of drinking water

- information about risk - it means to exchange information and opinions of threats, risk and factors connected with risk, during risk analysis, between risk managers, consumers, producers, traders, and scientists.

- $\quad$ procedure - it is an established pattern of conduct - a description of activities to enable the execution of certain task,

- instruction - it is an operational procedure of a lower order - it gives detailed steps in a logical sequence of implementation, describes step by step the task of the job, explains its implementation. 


\section{Defining the risk for the systems of collective water supply}

\subsection{Introduction}

In the safety analysis, assuming the appearance of undesirable events according to the exponential distribution of failure free operation time, the probability of such an event (failure) is determined by the formula:

$$
Q=1-\exp (-\lambda t)
$$

In risk assessment $\lambda \cdot t<1$, then the probability $Q$ can by approximated:

$$
Q=\lambda t
$$

It allows to conclude that, regardless of the value of failure intensity $\lambda=$ const, an increase in the risk exposure is associated with time $t$ and always results in an increase of that risk.

The classic definition of a quantitative risk $\mathrm{r}$ is the product of the probability of incident $\mathrm{P}$ and its negative consequences C (Faber \& Steward 2003, Haimes 2009, Kaplan \& Garrick 1981, Kaplan 1997):

$$
\mathrm{r}=\mathrm{P} \cdot \mathrm{C}
$$

The consequences can be determined in the range from zero to one, while $\mathrm{C}=1$ is attributed to decease (Guikema \& Pate-Cornell 2002). In this way, limited to such case, $r=P$.

In epidemiology the concepts of absolute risk and relative risk have been distinguished. The absolute risk is a number of observed cases $\mathrm{O}$ and expected cases $\mathrm{E}$ in a given human population. The relative risk is calculated from the formula (Rak 2003):

$$
\mathrm{rr}=\frac{\mathrm{O}}{\mathrm{E}}
$$

Often the so called excess relative risk is also calculated from the formula:

$$
\text { err }=\frac{O-E}{E}
$$

The magnitude of the risk can be also related to person-years number PY. Then the formula (4) take the form:

$$
\text { err }=\frac{O-E}{P Y}
$$

For example, if $\mathrm{rr}=1,4$, this means that the excess relative risk is 0.4 , representing an increase of $40 \%$ over the normal frequency of deaths due to the poisoning by the contaminated water. It is believed that the risk of fatal disease caused by the consumption of poisoned water is proportional to a dose. This is a known hypothesis resulting from the assumption of additivity of effects. However, there is a discussion of "high" and "low" dose. In the health risk assessments remains a problem of consistency of mentioned above hypothesis in the field of low-dose (Johanson 2008). An illustration of this may be the following reasoning: if the dose caused a lethal effect with a probability of 0.2 , for example, 200 deaths for every 1,000 people, it is by no means clear that a dose 100 times smaller will cause two deaths for every 1,000 people. Undoubtedly it is true that this is not clear but it is 
not true that it can not be. Seveso II directive 96/82/EC Seveso 1996) on the control of major accident hazards involving dangerous substances is applicable from 3 February 1999. It introduces the concept of:

- $\quad$ major accident prevention policy (MAPP),

- $\quad$ safety management system (SMS),

- major accident prevention strategy (MAPS),

- $\quad$ plant with increased risk (PIR), plant with high risk (PHR), internal emergency plan (IEP), external emergency plan (EEP),

- $\quad$ safety report (SR).

In the article 3 of this directive there is a definition of major accident, which means " an occurrence such as a major emission, fire, or explosion resulting from uncontrolled developments in the course of the operation of any establishment covered by this Directive, and leading to serious danger to human health and/or the environment, immediate or delayed, inside or outside the establishment, and involving one or more dangerous substances". In the article 8 there is a new term - domino effect, meaning the sequence of events leading to a major accident. Seveso II Directive introduces risk analysis. It is postulated that the risk analysis does not only consist in demonstrating the potential likelihood of death .A product of the negative environmental and social effects and frequency of undesirable events associated with them is the basis of risk analysis and to draw appropriate conclusions. Preliminary hazard analysis (PHA) should be used as a technique for estimating the risk (Hellier 2000). If possible threats should be eliminated or reduced at source through methods that improve safety. It can be done based on past practices that has already been proved. The methods of achieving this objective are (Ezell et al. 2000, Li\& et al. 2009, Macgillivray et al. 2007):

- $\quad$ risk should be as low as reasonably achievable (ALARA)

- $\quad$ risk should be as low as reasonably practicable (ALARP)

- the use of the best accessible technology - (BAT), in the manufacturing process and in major accidents prevention.

\subsection{Risk valuation}

Currently, the global trend is the maximum acceptable individual risk not greater than $10^{-6}$ per year, while the group risk $10^{-5}$ per year.

It is assumed that the level of individual risk between $10^{-4}$ and $10^{-6}$ per year requires risk/cost-benefit analysis (RCBA) to be carried out in accordance with the ALARP principle (risk as low as reasonably practicable).

British legislation (the Health and Safety Executive) accepts the maximum voluntary risk level $10^{-3}$ per year, but the imposed group risk related to industrial hazards $10^{-4}$ per year, for at least 10 years.

The ALARP principle is used in many different areas to analyse the risk associated with industrial activity (Faber \&Steward 2003, Hrudey\& Hrudey 2004, Pollard et al.2004, Rak 2003). It is assumed that:

- the upper limit of the ALARP area is:

- for workers $10^{-3}$ deaths per year

- for the public $10^{-4}$ deaths per year

- the lower limit of the ALARP area is:

- for workers and the public 10-6 deaths per year 
The equivalent fatality rate , 1 death $=10$ major injuries $=200$ minor injuries, is applied..

The acceptance of risk by the people is the following:

- $\quad 10^{-8}$ (one death per year per every 100 million people) - the threat is felt incidentally,

- $\quad 10^{-6}$ (one death per year per every million people) - these incidents are reported, but any special procedures to counteract actively to such threat are not taken,

- $10^{-4}$ (one death per year per 100,000 people) - citizens are demanding organized protective action,

- $10^{-2}$ (one death per year per 100 people) - the risk of this kind should be reduced individually.

Historical analysis of undesirable catastrophic events in technical systems indicate that they are caused by 3 to 5 failures occurring simultaneously at the same time or in the small interval.

\subsection{The concept of microrisk}

The concept of microrisk associated with human activities was introduced by G. Marx.

He defined it as a risk of death as a result of performing given activity per one million people. In this way, the size of the risk can be given in units of [microrisk / year]. For example, the size of the risk for human labour in some sectors of the economy is (Haas 1999.):

- $\quad$ work in the electromechanical plant 100 microrisk/year, that is $10^{-4}$

- work in the coal mine 800 microrisk/ year, that is $8 \cdot 10^{-4}$,

- work at high voltage lines 1,200 microrisk/ year, that is $1,2 \cdot 10^{-3}$,

- $\quad$ work in oil platforms 1800 microrisk / year, that is $1,8 \cdot 10^{-3}$

Selected human daily activities corresponding to 1 microrisk are:

- breathing polluted air in urban smog for $10 \times 24 \mathrm{hrs,}$

- $2500 \mathrm{~km}$ of travelling by train,

- $2000 \mathrm{~km}$ of travelling by plane,

- $100 \mathrm{~km}$ of driving by car,

- $\quad$ working in the industrial plant for 5 days

Using the concept of microrisk seems to be very clear and widely accepted. The above data show that air travel is safer than driving by car.

- travelling by plane

1 microrisk $=2000 \mathrm{~km}$, that is

$\frac{1}{10^{6}}=2000 \mathrm{~km}$

1 death $=2,0 \cdot 10^{9} \mathrm{~km}$ or 0,5 death per $10^{8} \mathrm{~km}$

- driving by car

1 microrisk $=100 \mathrm{~km}$, that is

$\frac{1}{10^{6}}=100 \mathrm{~km}$

1 death $=10^{8} \mathrm{~km}$ or 10 deaths per $10^{9} \mathrm{~km}$

\subsection{The health risk in the use of public water supply-examples}

\section{Risk of death}

The number of deaths 10 and individual risk of $10^{-5}$ were assumed as a threshold value for highly developed countries. In the case of an increase of this threshold value for a given 
public water supply, the risk of death should be reduced in inverse proportion to the number of injured people. The relationship of risk versus the expected number of victims is shown in Figure 1.

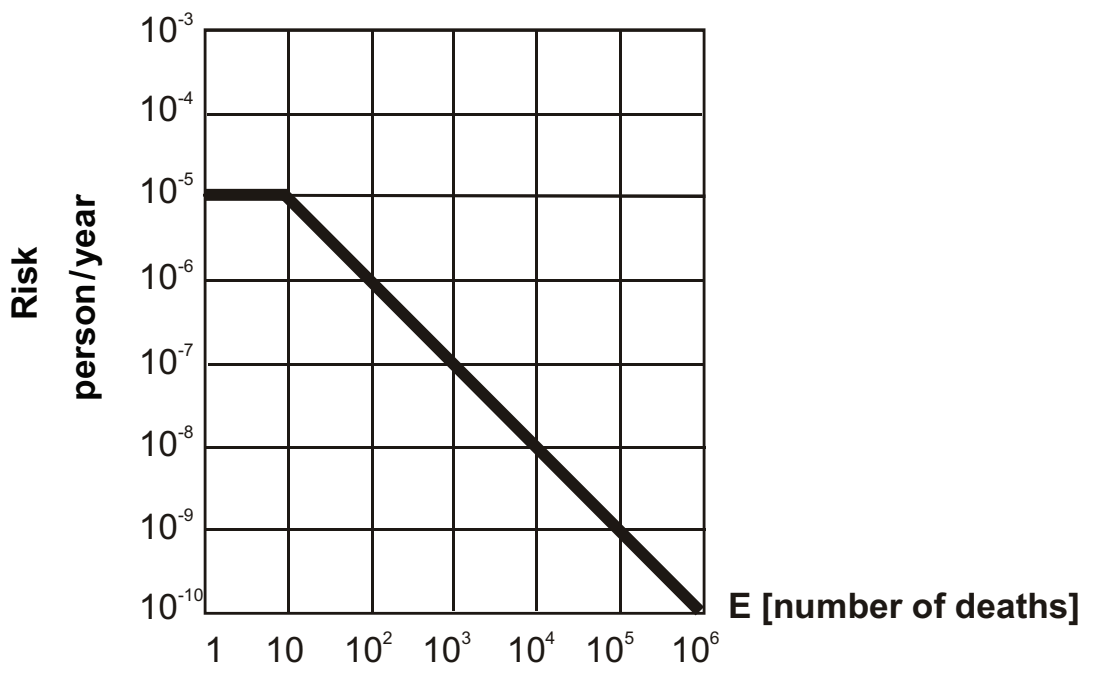

Fig. 1. Acceptable risk of death

\section{Risk of chronic injury}

The number of chronic injuries 10 and individual risk of $10^{-4}$ were assumed as a threshold value. The relationship of risk versus the expected number of victims is shown in Figure 2.

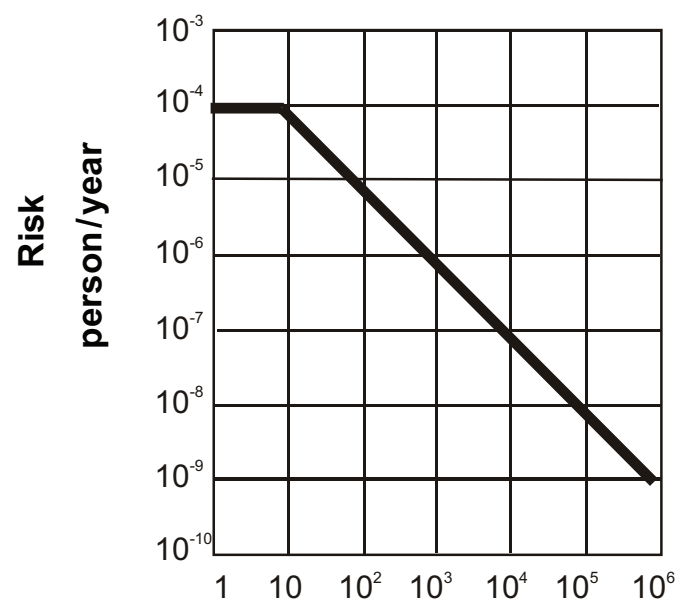

\section{$E$ [number of chronic} injuries]

Fig. 2. Acceptable risk of chronic injury

\section{Risk of gastric ailments}

The number of gastric ailments 100 and individual risk of $10^{-3}$ were assumed as a threshold value. The number of chronic injuries is shown in Figure 3. 


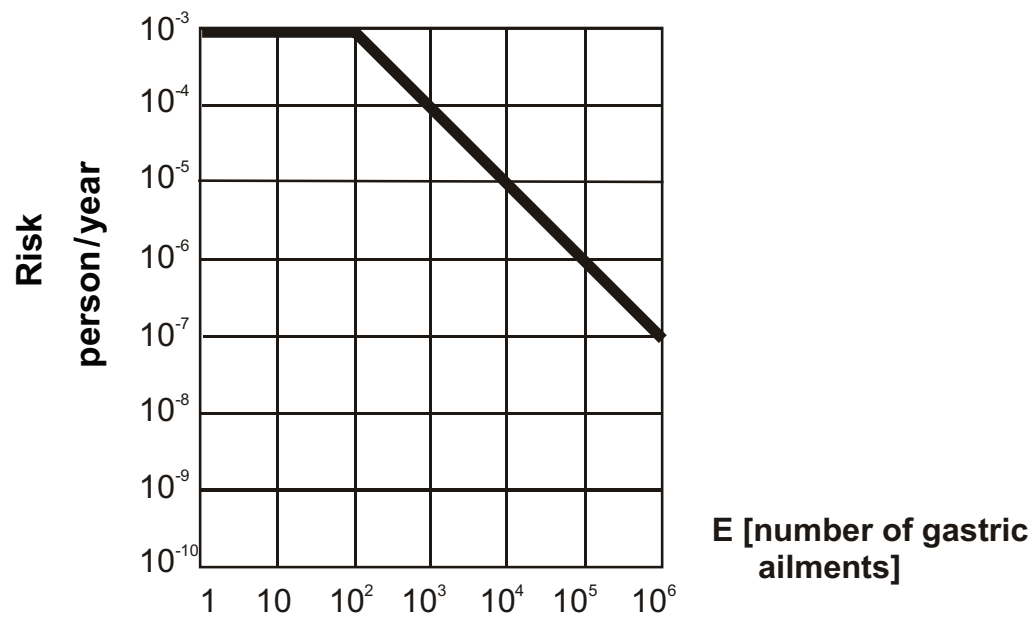

Fig. 3. Acceptable risk of gastric ailments

\section{The methodology of the HACCP system for systems of collective water supply}

The HACCP system is one of the systems ensuring quality and health benefits of drinking water (Havelaar 1994). The implementation of the system improves trust among the particular participants of drinking water market. The beneficiaries of the effects of the introduction of the HACCP system are manufacturers, retailers, supervisor service, and, above all, consumers. A well-functioning HACCP system allows to avoid unjustified claims, protects against the loss of trust and reliability of water supply companies in the market External benefits from the introduction of HACPP by the company producing drinking water are:

- the increase of consumers confidence,

- the improvement of the image of the company,

- $\quad$ the increase of confidence at official inspection units.

- the increase of water consumers safety

The HACCP system is a change of philosophy in assessing the quality of drinking water as a product.. The assessment of the conditions of drinking high quality drinking water production, instead of only final control, ensures the increase of health safety connected with water consumption. The HACCP system is a procedure to ensure the safety of drinking water by identifying and assessing the scale of threats in terms of health quality and risk of threats during all stages of drinking water manufacturing. This system also aims to identify ways to reduce threats and to establish corrective actions.

The HACCP system for food control was created in the U.S. in the late sixties of last century, at the request of NASA - (National Aeronautics and Space Administration). The origin of HACCP was related to the scientific research on food for astronauts free from pathogenic micro-organisms.

In 1971 Pollsburgy company presented this system at the American National Conference for Food Protection. The HACCP system has been accepted by World Health Organization (WHO) and International Commission on Microbiological Specifications for Foods (ICMSF). 
As a result of Polish accession to the European Union industry for the production and distribution of drinking water was obliged to apply the HACCP system. It is considered the most effective tool to ensure that food which is water will not be contaminated or polluted and will be safe for consumers health. The HACCP system is created individually for each production line and the type of distribution, taking into account the specific character of the given activity.

The main principles are:

- the identification of the possible biological, chemical and physical threats and the methods of counteraction,

- prevention, in form of a control of the particular phases of drinking water production process and distribution, not just the final product,

- applied in the entire production cycle, from water intake, through treatment, storage, distribution to consumers.

There are seven basic stages of implementing the HACCP system (Havelaar 1994):

\section{Step 1. Threats analysis}

It consists of:

- the identification of potential threats in the category of occurrence: biological, chemical, physical. The medical reports indicate that $90 \%$ of diseases resulting from poor quality water consumption is caused by its microbiological contamination,

- the establishment of a source and a reason, as well as the preventive activities, (general procedures, direct actions),

- the assessment of risk of threat.

The following definition of risk was taken:

Risk (R) is an arranged four element set (Rak\&Tchorzewska 2006, Tchorzewska 2007) :

$$
\mathrm{r}=\left(\mathrm{S}_{\mathrm{i}}, \mathrm{P}_{\mathrm{Si}}, \mathrm{C}_{\mathrm{Si}}, \mathrm{O}_{\mathrm{Si}}\right)
$$

The formula used to determine the measure of risk is the following:

$$
\mathrm{r}=\frac{\mathrm{P}_{\mathrm{Si}} \mathrm{C}_{\mathrm{Si}}}{\mathrm{O}_{\mathrm{Si}}}
$$

where:

$S_{i}$ - representative emergency scenario $i$, described as a series of successive undesirable events,

$\mathrm{P}_{\mathrm{Si}}$ - point weight related to the probability that i representative emergency scenario $\quad \mathrm{S}_{\mathrm{i}}$ appears,

$\mathrm{C}_{\mathrm{Si}}$ - point weight related to the size of losses caused by i representative emergency scenario $\mathrm{S}_{\mathrm{i},}$

$\mathrm{O}_{\mathrm{Si}}$ - point weight related to the WSS protection against i- representative scenario $\mathrm{S}_{\mathrm{i}}$ (protective barriers: clean water tanks, monitoring system etc.)

the WSS protection system - $\mathrm{O}$ - is inversely proportional to the size of the risk. The more extended system of protective barriers, the less risk of threat to water consumer safety The proposed method is an expert method, and in such cases, the predefined values of risk assessment as descriptive measures of parameters included in the formula for risk determination, are used.. Every time some level of weight is assigned to the parameters $\mathrm{P}_{\mathrm{Si}}$, $\mathrm{C}_{\mathrm{Si}}$ and $\mathrm{O}_{\mathrm{Si}}$, according to the following point scale : 
- $\quad$ low $-\mathrm{L}=1$

- $\quad$ medium $-\mathrm{M}=2$

- $\quad$ high $-\mathrm{H}=3$

In this way the point risk scale in the numerical form, within the range $[0,33 \div 9]$, has been obtained.

\begin{tabular}{|c|c|c|c|c|c|c|c|c|}
\hline \multicolumn{9}{|c|}{$\mathrm{P}=\mathrm{L}=1$} \\
\hline \multicolumn{9}{|c|}{ C } \\
\hline \multicolumn{3}{|c|}{$\mathrm{L}=1$} & \multicolumn{3}{|c|}{$M=2$} & \multicolumn{3}{|c|}{$\mathrm{H}=3$} \\
\hline \multicolumn{9}{|c|}{$\mathrm{O}$} \\
\hline $\mathrm{H}=3$ & $M=2$ & $\mathrm{~L}=1$ & $\mathrm{H}=3$ & $M=2$ & $\mathrm{~L}=1$ & $\mathrm{H}=3$ & $\mathrm{M}=2$ & $\mathrm{~L}=1$ \\
\hline \multicolumn{9}{|c|}{$r$} \\
\hline LLH & LLM & LLL & $\mathrm{LMH}$ & LMM & LML & $\mathrm{LHH}$ & LHM & LHL \\
\hline 0,33 & 0,5 & 1 & 0,66 & 1 & 2 & 1 & 1,5 & 3 \\
\hline \multicolumn{9}{|c|}{$\mathrm{P}=\mathrm{M}=2$} \\
\hline \multicolumn{9}{|c|}{$\mathrm{C}$} \\
\hline \multicolumn{3}{|c|}{$\mathrm{L}=1$} & \multicolumn{3}{|c|}{$M=2$} & \multicolumn{3}{|c|}{$\mathrm{H}=3$} \\
\hline \multicolumn{9}{|c|}{$\mathrm{O}$} \\
\hline $\mathrm{H}=3$ & $M=2$ & $\mathrm{~L}=1$ & $\mathrm{H}=3$ & $M=2$ & $\mathrm{~L}=1$ & $\mathrm{H}=3$ & $M=2$ & $\mathrm{~L}=1$ \\
\hline \multicolumn{9}{|c|}{$\mathrm{r}$} \\
\hline MLH & MLM & MLL & $\mathrm{MMH}$ & MMM & MML & $\mathrm{MHH}$ & MHM & MHL \\
\hline 0,66 & 1 & 2 & 1,33 & 2 & 4 & 2 & 3 & 6 \\
\hline \multicolumn{9}{|c|}{$\mathrm{P}=\mathrm{H}=3$} \\
\hline \multicolumn{9}{|c|}{ C } \\
\hline \multicolumn{3}{|c|}{$\mathrm{L}=1$} & \multicolumn{3}{|c|}{$M=2$} & \multicolumn{3}{|c|}{$\mathrm{H}=3$} \\
\hline \multicolumn{9}{|c|}{$\mathrm{O}$} \\
\hline $\mathrm{H}=3$ & $M=2$ & $\mathrm{~L}=1$ & $\mathrm{H}=3$ & $M=2$ & $\mathrm{~L}=1$ & $\mathrm{H}=3$ & $M=2$ & $\mathrm{~L}=1$ \\
\hline \multicolumn{9}{|c|}{$\mathrm{r}$} \\
\hline HLH & HLM & HLL & $\mathrm{HMH}$ & HMM & HML & $\mathrm{HHH}$ & HHM & HHL \\
\hline 1 & 1,5 & 3 & 2 & 3 & 6 & 3 & 4,5 & 9 \\
\hline
\end{tabular}

Table 1. The three parametric risk matrix

Description of the parameters of risk factors according to the formula (7):

- The category of probability of failure - $\mathrm{P}$

- low probability - once in 10-100 years - $\mathrm{P}=1$;

- $\quad$ medium probability - once in 1-10 years $-\mathrm{P}_{\mathrm{i}}=2$;

- high probability -1-10 times a year or more often $-\mathrm{P}=3$. 
- $\quad$ The category of consequences - C

- small - perceptible organoleptic changes in water, isolated consumer complaints, financial losses up to $5 \cdot 10^{2}$ EUR - C=1;

- medium - considerable organoleptic problems (odour, changed colour and turbidity), consumers health problems, numerous complaints, information in local public media, financial losses $10^{2}$ EUR- C=2;

- large - endangered people require hospitalisation, professional rescue teams involved, serious toxic effects in test organisms, information in nationwide media, financial losses over $10^{3} \mathrm{EUR}-\mathrm{C}=3$.

- The category of protection - O

- low protection level - $\mathrm{O}=1$, municipal water quality standard monitoring, according to valid standards (monitoring at selected points of WSS that are equally distributed throughout the water supply system, in particular: water intake, WTP control points shown in fig.1, the places where water is fed into the network, selected points of the water network )

- medium protection level - $\mathrm{O}=2$, greater than normal monitoring of WSS ( total network monitoring e.g. utilising SCADA software ( Tchorzewska 2009)),

- high protection level - $\mathrm{O}=3$, special monitoring (e.g. within the framework of the multi-barrier system, including raw water biomonitoring based on test organisms, and use of industrial television with movement detectors on strategic objects ).

The point weights presented above are a proposal to the preliminary risk assessment and can be modified for a given WSS. The advantage of the presented method is the possibility to compare risk Table 2 summarizes the risk categories and corresponding point scales. According to the matrix for risk assessment given in Table 1 we can analyse different undesirable events, taking the following scale of risk

\begin{tabular}{|l|l|}
\hline Risk categories & Point scale \\
\hline Tolerable & $0,33 \leq \mathrm{r} \leq 1,0$ \\
\hline Controlled & $1,5 \leq \mathrm{r} \leq 3,0$ \\
\hline Unacceptable & $4,0 \leq \mathrm{r} \leq 9,0$ \\
\hline
\end{tabular}

Table 2. Risk categories

\section{Step 2. The establishment of critical control points (CCP)}

Critical control point in a WSS is a point, step or procedure which allows for control and prevention, eliminating or reducing risks associated with the possibility of losing the safety of water consumers to an acceptable level It enables to achieve the purpose of the system through the control of drinking water health safety .The condition of CCP determination is the possibility to monitor it and control the threat.. To determine CCP we can use a decision tree method. It allows to determine CCP through a logical sequence of questions and answers concerning the possibility to eliminate or reduce threat at a given point to the acceptable level. Below you can see the exemplary decision tree questions, according to the Dutch procedures.

Question 1

Are there any preventive measures in relation to the given threat?

Yes: go to question 2

No: go to question $1 \mathrm{a}$ 


\section{Question $1 a$}

Are preventive measures necessary in terms of health safety?

Yes: go to question $1 \mathrm{~b}$ No: it is not a CCP

Question $1 b$

Is the threat controlled by standard procedures?

Yes: it is not a CCP No: modify the process or/and preventive measures

Question 2

Does the given preventive measure eliminate or reduce the threat to the acceptable level?

Yes: go to question $4 \quad$ No: go to question 3

Question 3

Can contamination by the identified threat reach the inadmissible level or can it increase to the unacceptable level?

Yes: go to question $4 \quad$ No: it is not a CCP

Question 4

Can the threat be eliminated in the further process or can it be reduced to the tolerable level?

Yes: it is not CCP

No: it is CCP

\section{Step 3. The establishment of the critical limits for every control point}

After the establishment of the CCP, you must specify one or more indicators of contamination to be controlled, and the desired values, tolerances and unacceptable critical value. Index selection criterion should be the speed, ease and accuracy of measurement and the possibility of monitoring. In case of difficulties in this area the visual and/or sensor assessment should be used.

\section{Step 4. The establishment of CCP monitoring procedures}

The CCP monitoring is a base of the HACCP functioning. The results obtained from the monitoring have to be recorded. For monitoring procedures one should specify:

- a method of monitoring,

- a character, continuous or periodic,

- the frequency of periodic monitoring,

- a way of supervision,

- the principle of check and calibration of measuring devices

In Figure 1 the control points in the water production subsystem are presented.

For water distribution subsystem the scope of monitoring quality of water intended for human consumption in accordance with regulation covers the following range of indicators [5]:

- Physical and organoleptic parameters

- colour,

- turbidity,

- $\mathrm{pH}$,

- conductivity,

- smell

- taste

- Chemical parameters

- ammonium ion, 
- nitrite,

- nitrate,

- chlorine available

- $\quad \Sigma$ chlorates and chlorites,

- $\quad$ Fe and Mn for water from underground intakes

- Microbiological parameters

- Escherichia coli

- Enterococcus -

- coliform bacteria -

- Clostridium perfingens for water from surface water intakes

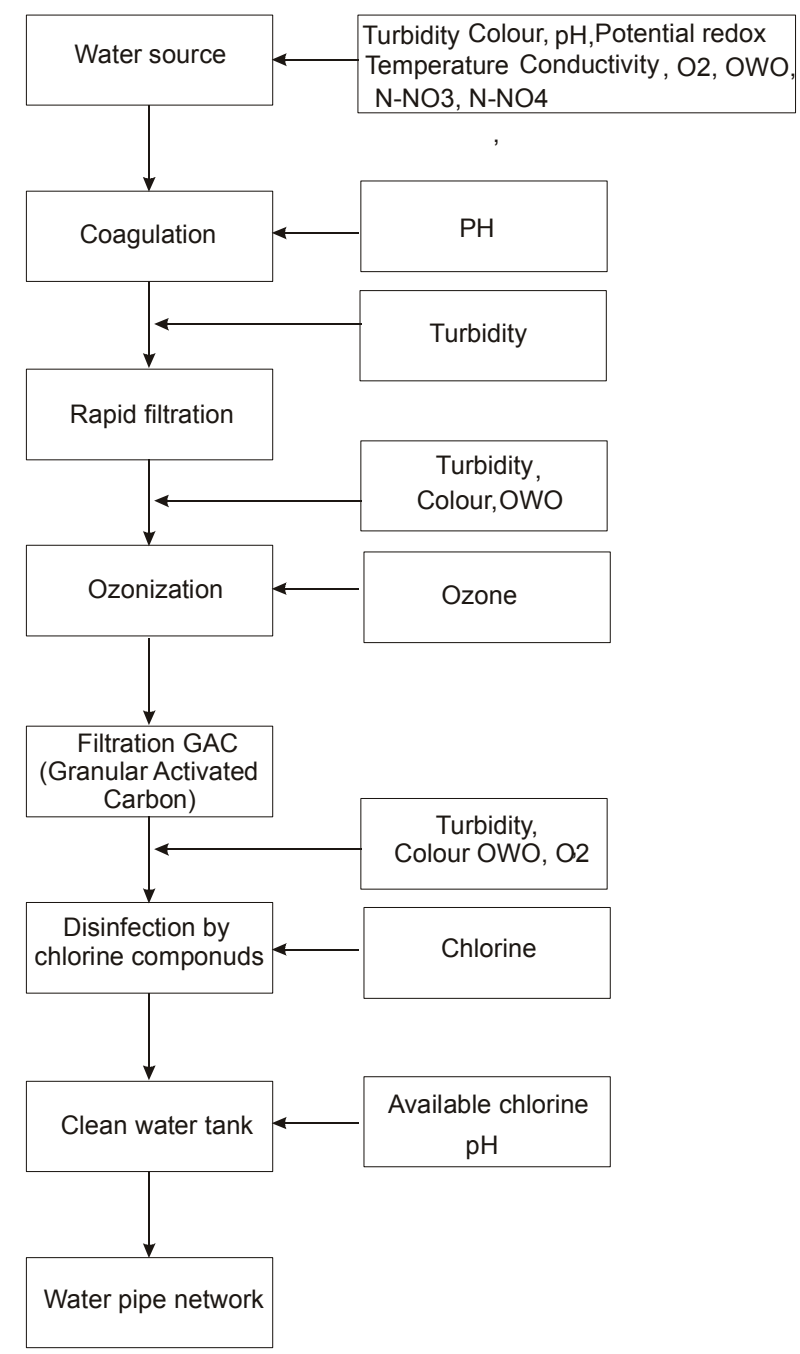

Fig. 4. Location of the control points and indicators of water treatment process quality 


\section{Step 5. The establishment of corrective actions}

Corrective action must be taken when monitoring shows a trend to exceed tolerated values of indicators of contamination or such values are exceeded. It should be possible to stop the process of drinking water production to remove the causes that led to corrective action

\section{Step 6. The establishment of system verification procedures}

Verifications are performed after the implementation of the HACCP system, as its first evaluation. Then the frequency of subsequent verifications should be established. Verification is always performed after making changes in the technological production process and also when the undesirable events occur.

Effectiveness of the HACCP system can be verified through internal and external audits. There is the possibility to obtain HACCP certificate which strongly increases the confidence of current and future consumers of tap water.

\section{Step 7. The creation of documentation}

System documents should contain a plan of HACCP and the records testifying system operation. The preparation, storage and monitoring of documents should be established.

\section{Conclusions}

- With regard to the management the modern WSS is characterized by centralization and decentralization. As for the risk, during normal system operation centralized control is necessary, while in periods of threats decentralized action is required.

- In the risk analysis one should not put the greatest emphasis on the accuracy of the results, but, above all, on the "success" or "failure" of projects related to improving the safety. The purpose of risk analysis is to provide the information necessary to make decisions related to risk reduction. In the European Union countries, from a methodological point of view, two kinds of approach to the problem of improving safety, are being observed.. These are qualitative and quantitative methods of risk assessment.

- The proposed methods for assessing risk associated with tap water consumption are compatible with current trend in a global scale.

\section{References}

Ezell B. \& Farr J. \& Wiese I.(2000) Infrastructure risk analysis of municipal water distribution system. Journal of Infrastructure Systems, ASCE. vol 6(3) ,pp: 118-122

Faber M. H. \&Steward M. G.(2003) Risk assessment for civil engineering facilities: critical overview and discussion. Reliability Engineering and System Safety, vol . 80, pp: 173-184.

Guikema S. D. \& Pate-Cornell M.E.(2002) Component choice for managing risk in engineered systems with generalized risk/cost functions. Reliability Engineering and System Safety, vol: 78, pp: 227-238.

Haimes. Y.Y. (2009). On the Complex definition of risk: a systems-based approach. Risk Analysis. vol 29(12), pp: 1647-1654.

Haas C.N\&Rose J.B \& gerba C.P (1999).Quantitive microbial risk assessment. John Wiley \& Sons. New York, USA.

Hastak H.\& Baim E, (2001). Risk factors affecting management and maintenance cost of urban infrastructure. Journal of Infrastructure Systems, ASCE, vol 7 (2), pp:67-75 
Hellier K (2000) Hazard analysis and critical control points for water supplies, 63rd Annual Water Industry Engineers and Operator's Conference, Warrnambool

Havelaar A.H . (1994).Application of HCCP to drinking water supply.Food control. Vol 5(3), pp:145-152

Hrudey, S.E. \& Hrudey, E.J. (2004) 'Safe drinking-water. Lessons from recent outbreaks in affluent nations'. IWA Publishing, London, UK.

Johanson B. (2008). Public Views on Drinking Water Standards as risk Indicators. Risk Analysis vol 28(6) pp: 1515-1530

Kaplan S\& Garrick BJ. (1981) On the quantitative definition of risk. Risk Analysis. vol1 (1), pp:11-27.

Kaplan S. (1997). The words of risk analysis. Risk Analysis, vol 7(4), pp:407-417.

Li, H. \& Apostolakis G. E. \& Gifun, J. \& Van Schalkwyk, W. \& Leite, S. \& Barber, D., (2009). Ranking the Risk from Multiple Hazards in a Small Community. Risk Analysis, vol:3, pp: 438-456.

MacGillivray BH\& Sharp JV\& Strutt JE \& Hamilton P.D \& Pollard S.J.T. (2007) Benchmarking risk management within the international water utility sector. Part I: design of a capability maturity methodology. Journal of Risk Research vol 10 pp: 85-104

Mays L.W. (2005). The role of risk analysis in water resources engineering. Department of Civil and Environmental Engineering, Arizona State University. www.public.asu.edu/twmays: 8-12.

Pollard, S.J.T. \& Strutt, J.E. \& Macgillivray, B.H. \& Hamilton, P.D. \& Hrudey, S.E. (2004). Risk analysis and management in the water utility sector - a review of drivers, tools and techniques. Process Safety and Environmental Protection vol. 82(B6), 1-10.

Rak J.(2003) A study of the qualitative methods for risk assessment in water supply systems. Oficyna Wydawnicza Politechniki Wrocławskiej. Environment Protection Engineering, vol.3 (4), pp:123-134.

Rak J. \& Tchórzewska-Cieślak B. (2006). Five - parametric matrix to estimate risk connected with water supply system operating Environment Protection Engineering. Wydawnictwo Politechniki Wrocławskiej. Vol 2, pp: 37-47

Rak J.(2009).Selected problems of water supply safety. Environmental Protection Engineering. Vol 35, pp: 29-35

Rosen, L. \&Lindhe, A. \& Hokstad, P. \& Sklet, S. \& Rostum J. \& Pettersson, T. J. R., (2008). Generic Framework for Integrated Risk Management in Water Safety Plans. 6th Nordic Drinking Water Conference, Oslo

Seveso II directive 96/82/EC (Safety Management System)

Tchórzewska-Cieślak B.(2007) Method of assessing of risk of failure in water supply system. European safety and reliability conference ESREL.2007 Risk, reliability and societal safety. Taylor \& Francis, t.2, Norway, Stavanger, s.1535-1539

Tchórzewska-Cieślak B,(2009). Water supply system reliability management. Environmental Protection Engineering. Vol 35 , pp.29-35

Water Safety Plans (Revised Draft), (2002) Report publication WHO/SDE/WSH/02.09 (World Health Organization, Geneva,.

WHO, (2004), Guidelines for Drinking Water Quality, 3rd edn. (draft) (World Health Organization, Geneva).

United States Environmental Protection Agency , 2006. Decision-Support tools for predicting the performance of water distribution and wastewater collection systems. Washington D.C.: National Risk Management Research Laboratory Office of Research and Development U.S. Environmental Protection Agency 


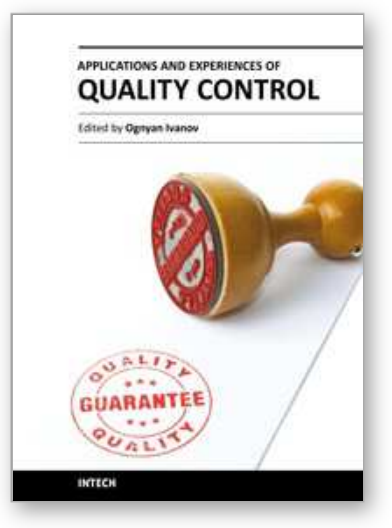

\section{Applications and Experiences of Quality Control \\ Edited by Prof. Ognyan Ivanov}

ISBN 978-953-307-236-4

Hard cover, 704 pages

Publisher InTech

Published online 26, April, 2011

Published in print edition April, 2011

The rich palette of topics set out in this book provides a sufficiently broad overview of the developments in the field of quality control. By providing detailed information on various aspects of quality control, this book can serve as a basis for starting interdisciplinary cooperation, which has increasingly become an integral part of scientific and applied research.

\section{How to reference}

In order to correctly reference this scholarly work, feel free to copy and paste the following:

Janusz Ryszard Rak and Barbara Tchórzewska-Cieślak (2011). Water Quality Control from the Perspective of Water Supply System Users' Safety, Applications and Experiences of Quality Control, Prof. Ognyan Ivanov (Ed.), ISBN: 978-953-307-236-4, InTech, Available from: http://www.intechopen.com/books/applications-andexperiences-of-quality-control/water-quality-control-from-the-perspective-of-water-supply-system-users-safety

\section{INTECH}

open science | open minds

\author{
InTech Europe \\ University Campus STeP Ri \\ Slavka Krautzeka 83/A \\ 51000 Rijeka, Croatia \\ Phone: +385 (51) 770447 \\ Fax: +385 (51) 686166 \\ www.intechopen.com
}

\author{
InTech China \\ Unit 405, Office Block, Hotel Equatorial Shanghai \\ No.65, Yan An Road (West), Shanghai, 200040, China \\ 中国上海市延安西路65号上海国际贵都大饭店办公楼405单元 \\ Phone: +86-21-62489820 \\ Fax: +86-21-62489821
}


(C) 2011 The Author(s). Licensee IntechOpen. This chapter is distributed under the terms of the Creative Commons Attribution-NonCommercialShareAlike-3.0 License, which permits use, distribution and reproduction for non-commercial purposes, provided the original is properly cited and derivative works building on this content are distributed under the same license. 